\title{
Echocardiography imaging of mitral annulus disjunction in a young female patient after sudden cardiac arrest
}

\author{
Radosław Piątkowski, Monika Budnik, Michał Kowara, Janusz Kochanowski, Grzegorz Opolski, \\ Marcin Grabowski
}

$1^{\text {st }}$ Department of Cardiology, Medical University of Warsaw, Warszawa, Poland

\author{
Correspondence to: \\ Monika Budnik, MD, PhD, \\ $1^{\text {st }}$ Department of Cardiology, \\ Medical University of Warsaw, \\ Banacha 1A, 02-097 Warszawa, \\ Poland, \\ phone: +48225992958, \\ e-mail: moni.budnik@gmail.com \\ Copyright by the Author(s), 2022 \\ DOI: 10.33963/KP.a2021.0146 \\ Received: \\ August 8, 2021 \\ Accepted: \\ October 27, 2021 \\ Early publication date: \\ October 29, 2021
}

A 38-year-old female patient was admitted to the hospital after successful resuscitation following sudden cardiac arrest (SCA). The primary recorded rhythm was ventricular fibrillation. In 2006, the patient had SCA caused by ventricular fibrillation, probably in the course of myocarditis. As part of secondary prevention, a cardioverter-defibrillator (ICD) was implanted. In the echocardiography exam, only small mitral regurgitation (MR) was diagnosed. Unfortunately, during hospitalization at another hospital in 2020, the device was removed leaving the ventricular electrode in the tissues due to its dysfunction and the lack of ICD therapies since 2006.

During current hospitalization, transthoracic echocardiography showed a normal left ventricular systolic function, and a severe MR due to bileaflet prolapse. Moreover, mitral annulus disjunction (MAD), measured from the left atrial wall-mitral valve leaflet junction to the top of the left ventricular wall during end-systole in the parasternal long-axis view, was revealed. The distance was $10 \mathrm{~mm}$ (Figure 1A; Supplementary material, Video S1). We did not observe an abnormal movement of the myocardium (curling), but a high velocity of systolic movement of the mitral annulus (the Pickelhaube sign) was present.

Transesophageal echocardiography showed severe multijet MR with pulmonary venous flow reversal (Figure 1B). In a 2D exam, bileaflet mitral prolapse (defined as superior displacement $\geq 2 \mathrm{~mm}$ of any part of the mitral leaflet beyond the mitral annulus) (Figure 1C). Three-dimensional transesophageal echocardiography (TEE 3D) showed additional information about the morphology and mobility of the leaflets. Valve leaflet thickening and a diffuse, redundant leaflet tissue with multiple segments bileaflet prolapse, chordae elongation, and annular dilatation were observed (Figure 1D; Supplementary material, Video S2). Finally, Barlow's disease with MAD was diagnosed.

Barlow's disease is more commonly observed in young and otherwise healthy patients and can be completely asymptomatic at the time of presentation [1]. MAD is associated with an increased risk of ventricular arrhythmias when it is present at the posterior wall [2]. Other markers of ventricular arrhythmia are female sex, younger age, previous syncope, more premature ventricular contractions, papillary muscle fibrosis, MAD $>8.5 \mathrm{~mm}$, and ECG changes [3-5]. The patient did not have any ICD intervention from 2006 to 2020, but, in our opinion, the worsening of MR was the factor leading to the second SCA. The decision about the implantation of subcutaneous ICD was made, at first, together with the cardiac surgeon who planned to operate on the patient. The patient was not qualified for emergency surgery. On the other hand, it was concluded that in secondary prevention, she should receive ICD before discharge. The patient was qualified for mitral valve repair by thoracoscopy. Subcutaneous ICD implantation is not a contraindication to this type of surgical access.

The patient had the subcutaneous ICD implanted and was referred to the cardio surgery department for surgical intervention.

The key message resulting from this case is that a detailed echo examination is crucial before the decision to remove implantable cardiac devices. In this particular case, performing an echocardiographic examination 


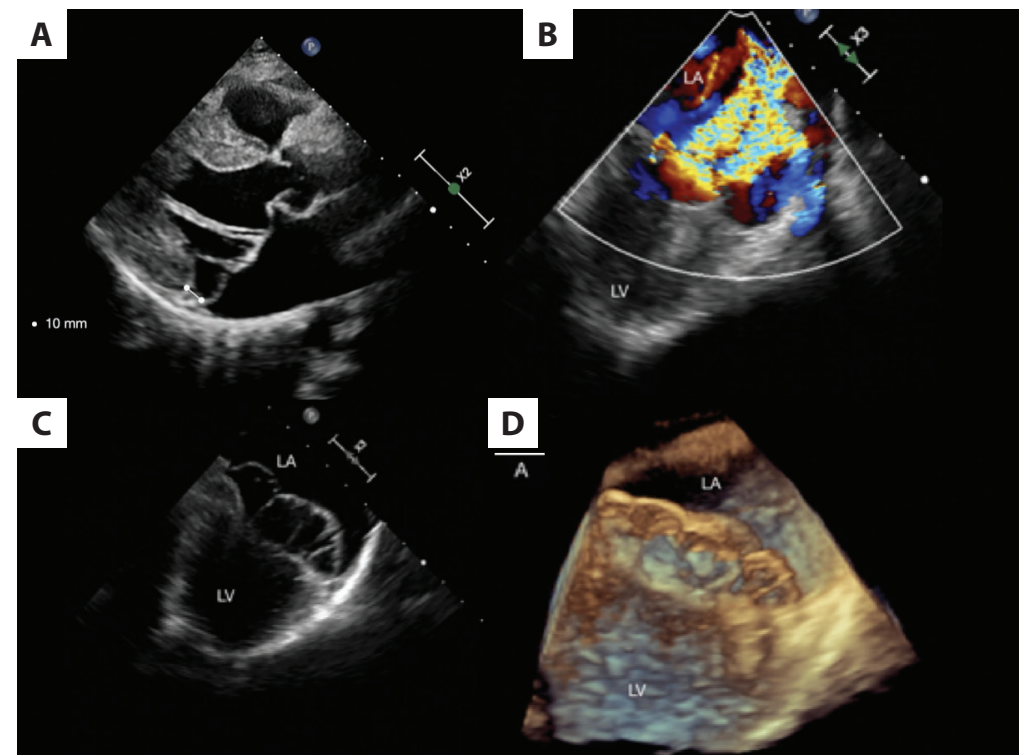

Figure 1. A. 2D transthoracic echocardiography, long-axis view. B. 2D TEE, color doppler on the mitral valve. C. 2D TEE, two-chamber view. D. 3D TEE, two-chamber view

Abbreviations: LA, left atrium; LV, left ventricle; TEE, transesophageal echocardiography

before removing the device would have led to replacing the device, instead of removing it, and could have prevented re-resuscitation.

\section{Supplementary material}

Supplementary material is available at https://journals. viamedica.pl/kardiologia_polska.

\section{Article information}

Conflict of interest: None declared.

Open access: This article is available in open access under Creative Common Attribution-Non-Commercial-No Derivatives 4.0 International (CC BY-NC-ND 4.0) license, allowing to download articles and share them with others as long as they credit the authors and the publisher, but without permission to change them in any way or use them commercially. For commercial use, please contact the journal office at kardiologiapolska@ptkardio.pl.

\section{REFERENCES}

1. Zienciuk-Krajka A, Daniłowicz-Szymanowicz L, Dorniak K, et al. Clinical characteristics of patients with arrhythmic mitral valve prolapse in a single tertiary center: prevalence of electrocardiographic and myocardial abnormalities. Kardiol Pol. 2021; 79(6): 693-696, doi: 10.33963/KP.a2021.0008, indexed in Pubmed: 34013515.

2. Dejgaard LA, Skjølsvik ET, Lie ØH, et al. The mitral annulus disjunction arrhythmic syndrome. J Am Coll Cardiol. 2018; 72(14): 1600-1609, doi: 10.1016/j.jacc.2018.07.070, indexed in Pubmed: 30261961.

3. Han $\mathrm{HC}, \mathrm{Ha}$ FJ, Teh $\mathrm{AW}$, et al. Mitral valve prolapse and sudden cardiac death: a systematic review. J Am Heart Assoc. 2018; 7(23): e010584, doi: 10.1161/JAHA.118.010584, indexed in Pubmed: 30486705.

4. Basso $C$, lliceto $S$, Thiene $G$, et al. Mitral valve prolapse, ventricular arrhythmias, and sudden death. Circulation. 2019; 140(11): 952-964, doi: 10.1161/CIRCULATIONAHA.118.034075, indexed in Pubmed: 31498700.

5. Książczyk M, Lelonek M. Mitral annulus disjunction as an incremental risk factor for ventricular arrhythmia in young patient. Kardiol Pol. 2021; 79(5): 581-582, doi: 10.33963/KP.15881, indexed in Pubmed: 34125937. 